\title{
Sellar Schwannoma
}

National Cancer Institute

\section{Source}

National Cancer Institute. Sellar Schwannoma. NCI Thesaurus. Code C155780.

An extremely rare schwannoma that arises from the sellar region. 